\title{
Design considerations related to the performance of erosion control systems combined with soil bioengineering techniques
}

\author{
P. Di Pietro \\ Officine Maccaferri S.p.A., Italy
}

\begin{abstract}
The combined use of erosion control systems (commonly referred to as "nonliving systems") and live plants for the restoration of waterways requires the standardization of terminologies, material performance, and design criteria for each system. This will yield the combination of a correct engineering approach with the appropriate best management practices to produce the desired long term performance. This paper focuses on combining soil bioengineering techniques with sound engineering practices when dealing with soil erosion or overall instability problems. The performance will be discussed with a proposed multidisciplinary approach, in order to achieve the desired environmental effect. The concept of "Minimum Energy Level" will also be discussed to identify the best environmentally compatible solutions, typically ranging from simple to complex design scenarios. Due to the combined presence of inert materials and living plants, the field performance of the various solutions will evolve over time. The contributing factor will require one to test the strength characteristics of the systems both in the short and in the long term, in close relationship with the field performance criteria, in order to understand their function in waterways. The dynamics of the project site and the overall structural stability are greatly affected by these decisions.
\end{abstract}

Keywords: soil bioengineering techniques, erosion control systems, material performance, overall stability, erosion control blankets, turf reinforcement mats, articulated concrete block, gabions, rip rap, minimum energy level. 


\section{Introduction}

Erosion control systems require standardized terminology and functions. This will be important to establish correct testing methods and ultimately to develop correct data interpretation. The following considerations will elaborate on the design and material performance.

Soil erodibility is governed by topographic, geologic, hydraulic and climatic variables. Soil movements occur when actual shear stresses exceed the soil's strength. Water is implied as either the controlling element or a primary controlling factor in 95 percent of all landslides (Varma, 1995, [1]). Accordingly, adequate drainage and diversion measures are without doubt among the most effective means of preventing landslides. In order to provide the most appropriate remedies, it is necessary to determine the conditions the triggered the instability. Even where the actual damage is restricted, the improvements may have to be extended over a wider stretch of the watercourse [1].

In general terms, a balanced multidisciplinary approach to soil erosion shall start from a correct determination of the following aspects:

1. Analysis of the problem (types of instability);

2. Identification of a suitable solution (type of system);

3. Application of adequate design methods (Performance Limits and critical factors);

4. Performance evaluation over time (Long Term Critical Factors).

\section{Typical instability problems}

Slope instability requires an evaluation of the hydraulic and the soil geotechnical parameters.

In all cases the incorporation of soil bioengineering techniques will allow the structure to "house" a living system which will contribute to a sound and sustainable solution, creating a suitable habitat and improving the overall environmental quality. In all instances the solution shall be chosen in relation to its ability to integrate with the surrounding environment in a sustainable manner [2].

The incorporation of vegetation through the use of soil bioengineering techniques will greatly improve the stability through the vegetative rooting system. However, vegetation will be effective after a certain period of time only, and this will imply that the design shall be performed both after construction with no vegetation (no additional strength and low channel roughness) and after years with vegetation (increased shear strength and high channel roughness) [3].

A brief summary of most typical instability problems is described in Table 1 below.

While in the first case (Drainage), the solution is to provide surface protection to reduce rainfall impact, run-off and scour, in the other cases a detailed geotechnical analysis of the slope stability may be required.

In this event solutions may require more in depth analyses resulting in a broader range of options, from seeding treatments to a variety of rolled erosion 
control systems (like biodegradable blankets or turf reinforcement mats), or ultimately to heavy-duty linings like concrete blocks, gabions, or rip rap, or even mass gravity wall systems, depending on the site conditions.

The preferable solution will offer the "Minimum Energy Level" to construct, commonly defined as the minimal environmental "disturbance", ranging from the lowest level (indentified at no intervention), to the highest level (even requiring the construction of a retaining structure, or similar type of intervention).

Table 1: $\quad$ Main causes of instability.

\begin{tabular}{|c|c|c|c|}
\hline CAUSE & EFFECT & LOCATION & RESULT \\
\hline $\begin{array}{l}\text { DRAINAGE } \\
\text { (Geotechnical) }\end{array}$ & $\begin{array}{l}\text { Surface } \\
\text { run off }\end{array}$ & $\begin{array}{l}\text { Slopes, } \\
\text { hills }\end{array}$ & $\begin{array}{c}\text { Loss of vegetation, } \\
\text { progressive } \\
\text { soil instability }\end{array}$ \\
\hline $\begin{array}{c}\text { SEEPAGE } \\
\text { (Geotechnical) }\end{array}$ & $\begin{array}{l}\text { Loss of } \\
\text { soil shear } \\
\text { strength }\end{array}$ & $\begin{array}{l}\text { Embankments, } \\
\text { slopes }\end{array}$ & Global instability \\
\hline $\begin{array}{c}\text { SCOUR } \\
\text { (Hydraulic) }\end{array}$ & $\begin{array}{l}\text { Formation of } \\
\text { scour holes }\end{array}$ & $\begin{array}{c}\text { River banks, } \\
\text { sea or lake shores }\end{array}$ & $\begin{array}{l}\text { Progressive soil } \\
\text { instability }\end{array}$ \\
\hline $\begin{array}{l}\text { TEMPERATURE } \\
\text { (Thermal) }\end{array}$ & $\begin{array}{l}\text { Formation of } \\
\text { cracks in the } \\
\text { soil/rock mass }\end{array}$ & $\begin{array}{l}\text { Cohesive soils, } \\
\text { Rock slopes }\end{array}$ & Rockfall \\
\hline
\end{tabular}

\section{Typical solutions}

In order to select the best system, the above concepts of combining erosion control systems with "soil bioengineering" using the principle of "Minimum Energy Level" will need to be applied [4].

Based on the general classification of types of instability previously described, typical solutions can be subdivided into lining systems which substantially provide a stability to erosion on the surface only, as opposed to wall systems which provide a geotechnical stability to a larger soil portion of the bank.

Within lining systems, as well as with mass gravity wall systems, natural or geosynthetic fiber blankets, geogrids and steel wire products can combine in a wide range of solutions which may incorporate soil bioengineering (Figs. 2, 3).

Soil bioengineering techniques have requirements, capabilities and limitations. Plant species shall be suitable for their intended use and they shall be adapted to the site's climate and soil conditions. They shall be selected based on the following conditions:

- Lack of fertile soil or moisture content to support the required plant growth; 
- Soil-restrictive layers, such as hardpans, may prevent the required root growth;

- Banks exposed to high water velocity or constant flooding.

The hydraulic effectiveness of a soil bioengineering technique depends upon vegetation growth, which is minimal immediately after installation and increases over time [4].

More importantly for wall systems, a careful analysis of the geotechnical soil stability will be required, to ascertain that no larger and deeper sliding phenomena will occur [5]. References to conventional methods to perform these analyses are extensively reported in technical literature and will not be discussed in this work.

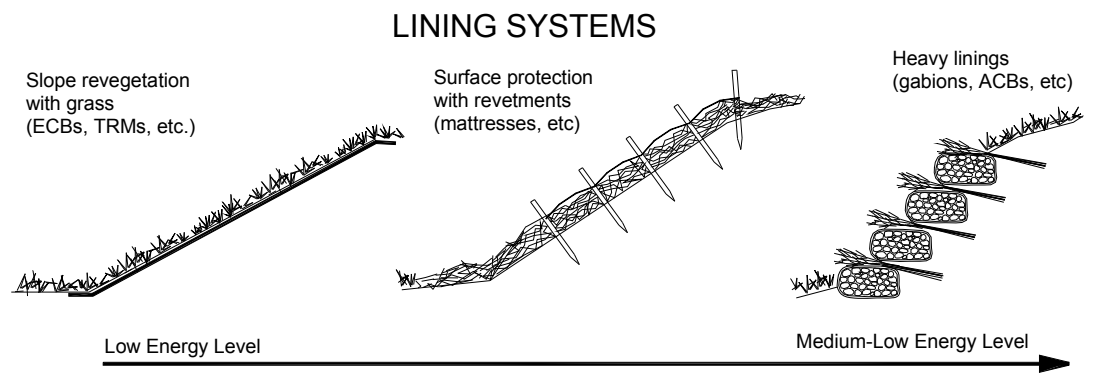

WALL SYSTEMS

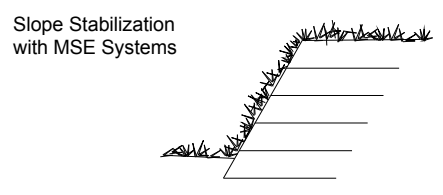

Medium-High Energy Level

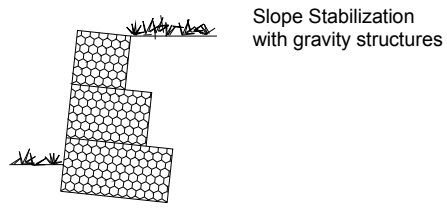

High energy level

Figure 1: $\quad$ Types of intervention from low (top left) to high (bottom right) energy level.

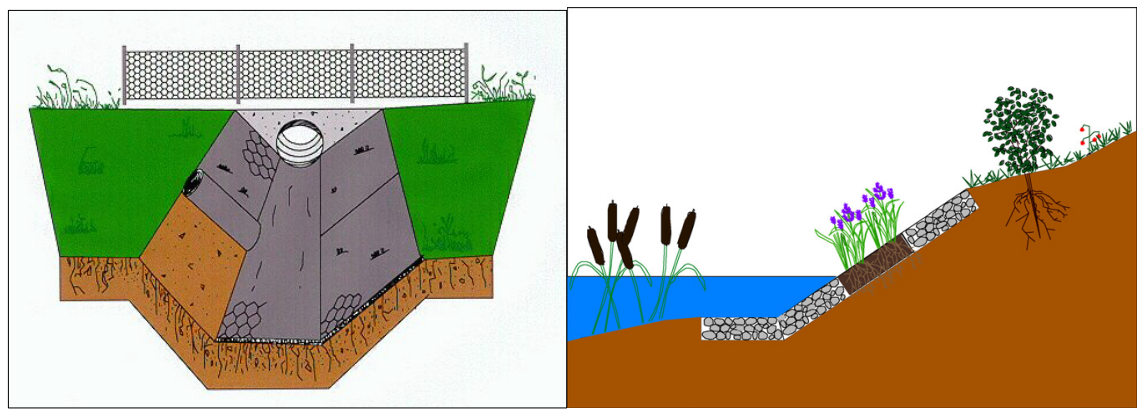

Figure 2: $\quad$ Typical solutions with lining systems. 


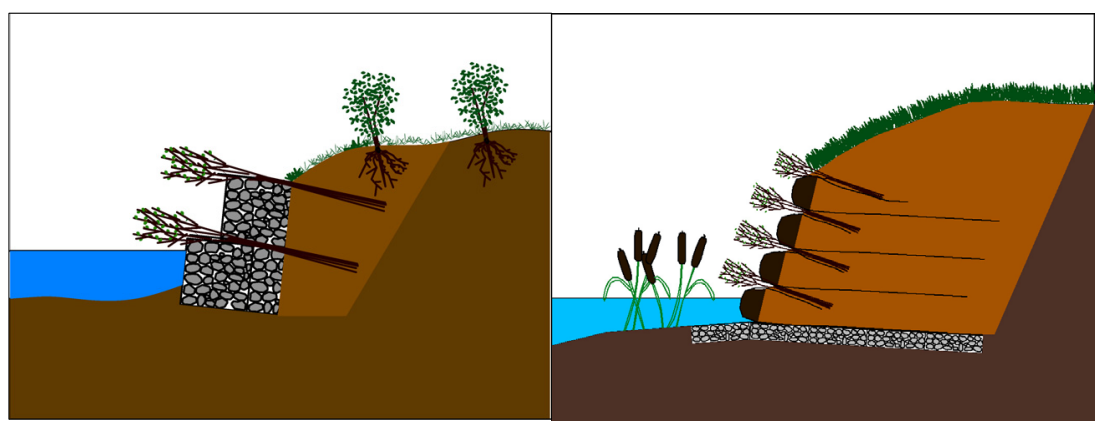

Figure 3: Typical solutions with wall systems.

\section{Performance testing and design considerations}

The performance of erosion control systems shall be determined by their ability to withstand hydraulic flow regimes both in the un-vegetated and vegetated condition.

It is important to establish common criteria for testing the failure of an erosion control system. When it is reasonable to say that failure is achieved is still a matter of interpretation subject to various points of view.

Experience indicates that a correct interpretation of performance limits shall be based on the risk associated with a failure propagation and the characteristic of the structure used.

Additionally, it shall be noted that erosion control systems may develop failure in different ways. Failure propagation in rock filled, or concrete, structures will develop in totally different ways (progressive or abrupt) and in different time frames (days or hours). This can be even more evident when testing various lining systems, such as light geosynthetics or biodegradable blankets. Serviceability limits would not be applicable using the same parameters.

In other words, what is considered as a performance limit for a wall structure cannot be the same for a lining system or for a soil bioengineering technique.

Lining systems will require a sub-classification in groups performing in a similar manner. In this case it is proposed to classify them in accordance with the following groups:

- Hard Armor Systems (sometimes termed "Heavy Duty Linings"). This category includes systems like Articulated Concrete Blocks (ACBs), Gabions or Rock mattresses, Rip rap, etc.;

- Light Systems (sometimes termed "Rolled Erosion Control Systems"). This category includes Erosion Control Blankets (ECBs), Turf Reinforcement Mats (TRMs), Geocells, etc.;

- Soil Bioengineering Techniques. This category includes many types of vegetative species, ranging from herbaceous or woody plants, to a wide variety of treatments and systems. Soil bioengineering techniques are often incorporated in the two above systems. 
Along with studying failure propagation criteria of various systems using comparable methods, equally data interpretation is also very important, as it will require that different design safety factors be considered among the various systems. This aspect is sometime disregarded in the engineering practice when designing in river environments.

It is important to associate a safety factor to each category of systems based on an actual failure propagation and to its risks associated (loss of lives, presence of infrastructures, cost of land, duration of the event, etc.).

\section{Hard armor systems}

In this category lining protections, due to their nature to stabilize by weight, are usually subject to minimal rupture propagation as they reach or moderately exceed the performance limits. Additionally, in the case of flexible systems the protection may not lose its effectiveness due to the ability to conform to the soil contours should the soil underneath be eroded moderately beyond an allowable threshold $[6,7]$.

Failure criteria should therefore be more related to the ability of the system to maintain a structural integrity. As mentioned, this aspect is intimately related to the degree of flexibility of the system used since it may be critical to the erosion propagation underneath the structure.

- Material failure: in hard armor systems can be identified when the material or a component breaks or a mechanical damage is observed;

- Performance failure: it is conventionally identified when, under a given flow regime, an established value of erosion depth is achieved. Allowable erosion depths should be related to the ability of the system to still provide a protection and effectiveness beyond the stability threshold and over the time. When soil bioengineering techniques are incorporated, additional tests shall be performed to measure the increased resistance after vegetation is established. This can be done by testing pre-vegetated systems in a controlled outdoor facility. The system's performance would require to be put in relationship with the equivalent vegetation growth rate, in order to correlate the test results with the field experience;

- Safety factors: in case of Hard Armor Systems, safety factors shall be related to the structural integrity and flexibility of the system used. These parameters are of primary importance to assess risks of failure propagation. For example, failure in a Rip Rap lining will develop differently from Articulated Concrete Block or from Gabion Rock Mattress lining. In the first case the initial motion of rocks will not be mechanically restrained by other rocks or other forms of confinement. It is therefore anticipated that a performance failure will coincide with a material failure. On the contrary, in the case of Articulated Concrete Blocks, the interlocking effect between the block units, as well as the confining effect of the wire basket in the case of rock mattress, will determine a material failure much above the achievement of a performance failure (initial motion). Since erosion protection systems shall be designed on their serviceability limit, it is 
reasonable to assume that safety factors shall be related on how far material failure from the performance failure is. These aspects are unfortunately not yet addressed in the current design practice.

\section{Light systems}

Commonly defined as Rolled Erosion Control Systems, these types of protection are generally relatively light in weight and thin, if compared to the more massive Hard Armor Systems. They are generally supplied in rolls, unrolled and laid on the slope, and stapled together. The performance of these lighter systems under a flow regime is sensitive to the duration of the event, and the effects may affect the ability to maintain a functional protection. The test duration is therefore a key factor to assess the long term performance. Tests should be performed both in the unvegetated and vegetated condition. The design shall be based on both situations.

- Material failure: light systems generally fail by losing continuity along the joints and a mechanical damage occurs by tearing and exposing the soil underneath to direct contact with flowing water;

- Performance failure: this type of failure occurs mostly when the erosion under the protection has progressed to a stage that the lining is no longer providing effective protection. A proposed criterion for performance failure is when a percentage of the total testing flume area reaches an average erosion depth of 1 inch (approx. $25 \mathrm{~mm}$ ). This criterion is related to the determination of a critical surface area where erosion depths become critical, and not only to a single point of measurement, as sometimes indicated in literature. A performance failure according to this interpretation is more representative of an actual critical field condition;

- Safety factors: they should be introduced and used for design to calculate the allowable shear stresses. The value of the safety factor for each system should be related to the potential effects of a failure propagation, and their ability to rapidly interact with the surrounding environment. A typical graph to represent the material performance is shown in Figure 4.

\section{Soil bioengineering}

This category, recently introduced in the American Standards (ASTM), focuses on the performance limits of vegetation alone in order to determine how much strength can be achieved (Fig. 5).

The effectiveness of any system incorporating soil bioengineering techniques is based on the adaptation of the living materials in their new environment. To test the resistance of these systems in a laboratory, a few parameters shall be considered like: stem density and length, root penetration, rooting habits, uniformity of vegetation, soil erodibility, and physical and chemical characteristics. These parameters will affect the growth and the establishment of the plants. The seasonal climate changes will also affect the resistance of the stream flow [8]. 


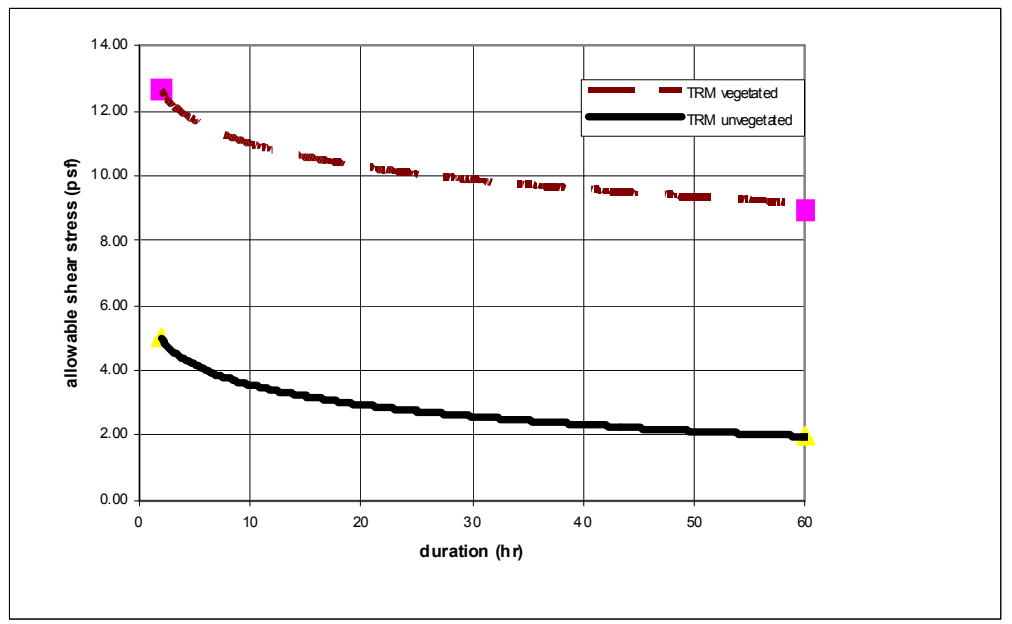

Figure 4: Allowable stresses vs. flood duration in vegetated and Unvegetated TRMs.

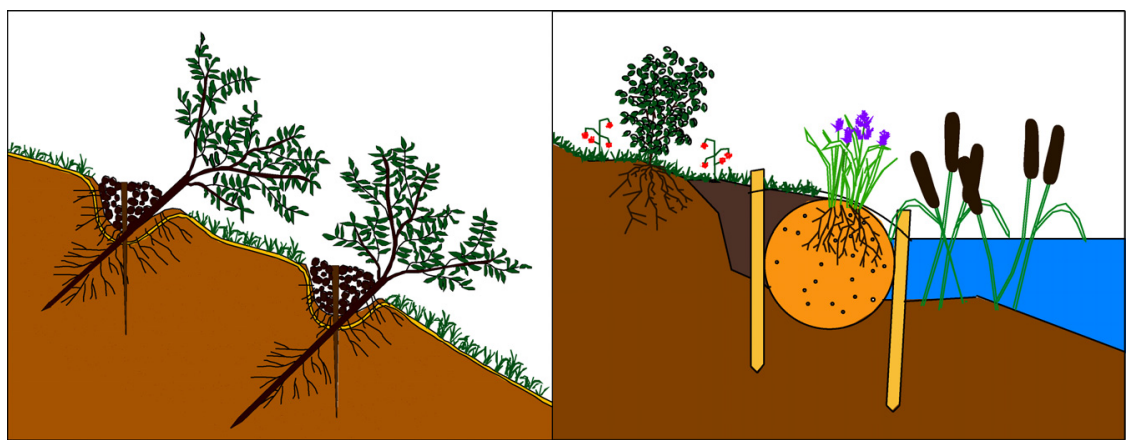

Figure 5: Typical examples of soil bioengineering techniques.

Most of these parameters have an effect on the flow regime. The resistance of the structure before and after vegetation establishment may be different. A minimum of two tests shall be performed:

- Short term resistance after installation, when the vegetation is not established.

- Long term resistance, after establishment of the vegetation.

\section{Conclusions and recommendations}

The design of environmentally balanced solutions implies the understanding of several factors. The current lack of standardized terminologies, testing methods and data interpretation does not always allow one to properly compare the different systems and their functions. This unfortunately can mislead the 
designer in the evaluation of the system's performance, ultimately resulting in an incorrect design or construction practice.

Erosion protection systems of any nature and type should be designed to perform immediately after the installation and have the ability to blend with the surrounding environment to achieve a perfect harmony.

To assist designers in the choice of the most appropriate erosion protection, more awareness on the importance that short and long terms stability factors is advised.

Standard test methods for assessing the degree of an erosion protection as well as their data interpretation and the sound design methods shall allow fairness and comparability between systems. Additionally, systems should be characterized by their ability to integrate and evolve with the surrounding environment.

Material failure or performance failures in erosion protection systems can be very different, even among systems grouped (or assumed) to be similar. They shall be interpreted correctly, in relationship to the end result in the field. The scope of this work is to underline the importance of creating new standards with this in mind.

\section{References}

[1] "Management of Sediment - Philosophy, Aims and Techniques", C.V.J. Varma - Sixth Intl. Symposium of River Sedimentation, New Delhi, 1995

[2] "Biotechnical and Soil Bioengineering Slope Stabilization", D. H. Gray, Robbin B. Sotir, John Wiley and Sons Inc., New York (1996)

[3] "Open Channel Hydraulics", Ven Te Chow, McGraw Hill (1988)

[4] "Hydraulic impacts of riparian vegetation - Summary of literature", J. Craig Fischenich, US Army Corps of Engineers - Waterway Experiment Station, Vicksburg (1997)

[5] "Code of Practice for Strengthened/reinforced soils and other fills", British Standard BS 8006, 1995

[6] "Flexible gabion and Reno mattress structures in river and stream training works". R. Agostini, L. Cesario, F. Ferraiolo, A. Papetti, Officine Maccaferri S.p.A. (1988)

[7] "Hydraulic tests to develop design criteria for the use of Reno mattresses", D.B. Simons, Colorado State University, Fort Collins (1984)

[8] "Vegetation and slope stability" pp. 187-230, Greenway, D.R., John Wiley Chichester (1987) 